\title{
Inclusão escolar: um estudo acerca da implantação da proposta em escolas públicas
}

\author{
Inclusão na escola pública
}

\author{
Nilza Sanches Tessaro Leonardo
}

\begin{abstract}
Resumo
Esse estudo teve por objetivo verificar como está ocorrendo o processo de implantação de projetos inclusivos em escolas públicas de ensino básico. Participaram da pesquisa treze professores que tinham alunos com necessidades educativas especiais em sua classe. Foi utilizado um questionário composto por quatro questões abertas. Os dados foram examinados mediante análise de conteúdo. Os principais resultados revelaram que as alterações ocorridas nas escolas relacionam-se quase exclusivamente à infra-estrutura física; em contrapartida, mostraram também haver escolas nas quais nem mesmo as adaptações neste aspecto foram realizadas. Os profissionais não receberam preparo/capacitação para desenvolver projetos inclusivos e a maioria deles pouco ou nada conhece sobre as deficiências e sobre a inclusão escolar. Concluiu-se que a inclusão escolar vem se efetivando sem a infra-estrutura adequada, seja em termos de recursos materiais seja de recursos humanos, podendo trazer mais prejuízos do que benefícios a quem dela faz parte.
\end{abstract}

Palavras- chave: Educação, Escola, Inclusão.

\section{Academic Inclusion: a study about its application in public schools}

\begin{abstract}
This study's main objective was to verify how the implementation of inclusive education projects has been developing in Brazilian public primary schools. Thirteen teachers whose classrooms include pupils with special needs participated in this investigation. A questionnaire composed of four open questions was used. The data collected was subjected to content analysis. The main results have shown that the changes in the schools occurred almost exclusively with their physical infrastructure; and that in some of them not even these modifications were executed. The professionals have not received any training that might help them develop inclusive projects. In addition, the majority of them have little or no knowledge at all of the students' deficiencies and of inclusive education. The indication is that educational inclusion has been done without adequate infrastructure, both human and material, and that the result might bring more damages than benefits to those participating in it.

Keywords: Education, School, Inclusion.
\end{abstract}

\section{Inclusión escolar: un estudio sobre la implantación de la propuesta en escuelas públicas}

\section{Resumen}

Este estudio tuvo como objetivo verificar como está ocurriendo el proceso de implantación de proyectos inclusivos en escuelas públicas de la enseñanza primaria. Participaron de la investigación trece profesores que tenían en su clase alumnos con necesidades educativas especiales. Fue utilizado un cuestionario compuesto por catorce preguntas abiertas. Los datos fueron examinados mediante análisis de contenido. Los principales resultados revelaron que las alteraciones ocurridas en las escuelas se relacionan casi exclusivamente a la infraestructura física. En compensación, también mostraron que hay escuelas en las cuales ni las adaptaciones en este aspecto fueron realizadas. Los profesionales no recibieron preparación/capacitación para desarrollar proyectos de inclusión, y la mayoría de ellos conoce poco o nada sobre las deficiencias y sobre la inclusión escolar. Se concluyó que la inclusión escolar viene efectuándose sin la infraestructura adecuada, sea en términos de recursos materiales o de recursos humanos, pudiendo traer más perjuicios que beneficios a quien hace parte de ella.

Palabras clave: Educación, escuela, Inclusión. 


\section{Introdução}

As pessoas com deficiências por muito tempo foram mantidas segregadas e praticamente privadas de convívio social. Apenas a partir do século XX, quando teve início sua desinstitucionalização e sua educação escolar é que se verificou uma melhor aceitação do deficiente. Mesmo assim, observam-se ainda práticas segregatórias, preconceituosas e discriminatórias em relação ao deficiente e à deficiência. Isto aponta para uma sociedade que, como relata Paula (1996), continua supervalorizando a capacidade intelectual, a competitividade, a produção, a beleza física, a independência e a individualidade, fazendo com que pessoas portadoras de alguma limitação ou que fujam aos padrões estabelecidos como normais sejam vistas como problemas e altamente desvalorizadas pela sociedade.

Pode-se afirmar que, mesmo depois de muitas discussões em torno da inclusão social, continua o deficiente sofrendo estigma e preconceito por sua diferença. Existe todo um discurso em prol da inclusão em vários segmentos da sociedade, entre os quais o ambiente escolar em que a inclusão vem se concretizando. A inclusão no âmbito educacional ganhou força com a Declaração de Salamanca, fruto da Conferência Mundial sobre Necessidades Educativas Especiais, realizada naquela cidade espanhola, em 1994, documento de grande importância que trata dos princípios, da política e da prática relacionados às necessidades especiais. Essa Declaração, segundo Abenhaim (2005, p.43), proclama, entre outros princípios, que "as pessoas com necessidades educativas especiais devem ter acesso às escolas comuns, que deverão integrá-las numa pedagogia centralizada na criança, capaz atender a essas necessidades".

Destarte, princípio da educação inclusiva consiste em que as escolas devem reconhecer e responder às diversas necessidades dos alunos, assegurando-lhes uma educação de qualidade que thes proporcione aprendizagem por meio de currículo apropriado, modificações organizacionais, estratégias de ensino, uso de recursos especiais, etc. Deve ser garantida às crianças com necessidades educativas especiais uma educação efetiva em que elas recebam atendimento de acordo com suas especificidades (Mendes, 2002). Vale lembrar neste momento que as escolas brasileiras, especialmente as públicas, têm enfrentado muitas dificuldades, pois não têm conseguido proporcionar aprendizagem acadêmica nem mesmo às crianças que não possuem deficiência, o que mostra ser muito baixo o investimento, não apenas no que diz respeito ao processo inclusivo, mas no sistema educacional como um todo.
Abenhaim (2005) pensa da mesma forma e afirma que atualmente, em sua maioria, as escolas se encontram muito aquém do que se deseja. Elas têm conseguindo quando muito transmitir um saber que não se sabe a que ou a quem se destina, e com isto acabam excluindo todos os indivíduos que se distanciem de um modelo previamente elaborado, impossibilitando assim o caminhar junto com a diversidade e até mesmo impedindo o desenvolvimento e a possibilidade de troca entre as pessoas. Enfim, para essa autora, a desestruturação escolar leva à interrupção dos sonhos de muitas pessoas.

Parece óbvio que incluir de fato pessoas com necessidades educativas especiais no sistema regular de ensino significa muito mais do que apenas possibilitar que elas se insiram no contexto social e usufruam o mesmo espaço físico dos considerados normais. Como afirma Gotti (1998), isto implica ações que envolvam toda a comunidade acadêmica - professores, alunos, pais e outros - na luta pela conscientização do direito à cidadania. Um verdadeiro trabalho de inclusão escolar coloca a sensibilização e a conscientização da comunidade acadêmica como pré-requisito fundamental para que se consiga refletir criticamente em torno de conhecimentos, informações e sentimentos de pessoas com deficiência. Para essa autora, inclusão escolar significa um novo paradigma no marco conceitual e ideológico, o qual precisa envolver políticas, programas, serviços, a comunidade, enfim. Para Abenhaim (2005), a escola ser inclusiva também não significa apenas ela abrir suas portas às crianças com necessidades educativas especiais, sem ao menos saber o que fazer com elas: muito mais do que isso, representa ver em cada uma delas um ser em desenvolvimento, que necessita de caminhos para desenvolver seu potencial. Mrech (2001) complementa afirmando que 0 aluno com necessidades educativas especiais deve receber um atendimento diferenciado de acordo com suas necessidades.

Veiga Neto (2005) chama a atenção para o fato de que tratar a questão da exclusão escolar como de ordem econômica, psicológica, ou mesmo pedagógica, significa muito reducionismo. Defende que qualquer política de inclusão deve envolver questões de ordem epistemológica, mas que antes são também de ordem política, social e cultural. Para esse autor, não basta incluir para diminuir os diferenciais de poder, de segregação, autoritarismo e exploração que atravessam essa sociedade.

Ao que tudo indica, a exclusão está posta a serviço de interesses históricos, e certamente está posta para ficar. Então fica muito difícil modificar uma escola que se constituiu ao logo do tempo obedecendo à lógica da exclusão, e mais complicado ainda se torna quando se toma consciência de que fazer isto num ambiente neoliberal, num ambiente de capitalismo avançado e de 
competição é praticamente impossível. Não bastam, portanto, competências técnicas para se lidar com as questões colocadas na inclusão; essas são importantes apenas como parte da solução e situam-se em condições necessárias, mas não suficientes. É no plano da ordem cultural, da política e da vida que deve ser pensada esta questão (Veiga Neto, 2005).

Em contrapartida, para Glat, Magalhães e Carneiro (1998), a escola inclusiva poderá deixar o plano imaginário a partir de condições muito especiais de recursos humanos, pedagógicos e materiais. Acreditam que 0 professor no contexto inclusivo precisa de preparo para lidar com as diferenças, com a diversidade de todos os alunos. Tesini e Manzini (1999) também alertam que inclusão escolar envolve professores bem-preparados e a definição de uma política que venha subsidiar princípios e práticas para atender às necessidades educativas especiais, construindo normas uniformes sobre a igualdade de oportunidades para as pessoas com deficiência. Entretanto, observa-se que, em sua maioria, as escolas se encontram praticamente destituídas da infraestrutura necessária para implantar projetos inclusivos, tanto no tocante aos aspectos físicos quanto a recursos humanos. Com isto acredita-se que os professores, na sua maioria, não estão sendo preparados para receber alunos com necessidades educativas especiais, sendo levados a sentir-se inseguros, preocupados e desamparados em sua profissão.

O estudo realizado por Mazzoni, Torres e Andrade (2000) confirma o despreparo dos professores e da escola para atender o aluno diferente/deficiente. Os estudantes cegos que participaram de sua pesquisa manifestaram insatisfação com a instituição, pois se consideravam estudando em condições desvantajosas, sem materiais específicos e com professores despreparados para atendê-los. Neste momento torna-se importante citar o estudo desenvolvido por Gasparetto (2001), o qual também deixa explícito o despreparo dos professores para atender alunos com necessidades educativas especiais. Em sua pesquisa, que envolveu professores e diretores do Ensino Fundamental de escolas públicas que atuavam com alunos com necessidades educativas especiais, verificou que $82,3 \%$ desses profissionais pouco ou nada conheciam sobre a área, e que 92,6\% não tinham formação específica para atender esses alunos.

O estudo desenvolvido por Machado (2003) aponta a necessidade de que o estabelecimento de uma política educacional na área de educação especial seja constituída de trabalho coletivo, com educadores de todas as instâncias, articulando as diferentes esferas do poder público, pais, alunos e pesquisadores, tendo como meta a explicação dos mecanismos e estratégias necessários à sua efetivação. Para Rey (2003), a inclusão apenas poderá se tornar efetiva quando houver, de fato, uma reestruturação da instituição escolar favorecida por políticas públicas que garantam recursos humanos $\mathrm{e}$ materiais, fazendo com que todos os envolvidos tomem consciência de que é possível construir saberes a partir das competências, habilidades e limitações dos seres humanos.

Destaca-se neste momento que a luta em prol da inclusão deve ter como objetivo que alunos com necessidades educativas especiais sejam bem-sucedidos em salas de aula do sistema regular de ensino. Neste sentido pode-se contar com as contribuições de Vygotsky (1997), que defendia a idéia de ensinar os alunos deficientes em classes comuns do sistema regular de ensino. Para ele, as escolas especiais acabavam por segregar essas crianças e limitar o desenvolvimento das suas funções psicológicas superiores. Ele entendia a criança deficiente como um ser capaz, com condições de aprendizagem e desenvolvimento semelhantes às da criança "normal", centrando-se no social, e não no biológico. Vygotsky (1997) colocava o defeito em segundo plano, tanto que acreditava que a educação social acabaria vencendo o defeito. Idealizava uma escola que não tivesse como meta sua adaptação às deficiências da criança, mas sim, que lutasse para vencê-las, principalmente no campo social. A tarefa da educação, para ele, era a de inserir a criança deficiente na vida social e criar compensações para sua insuficiência física.

Vygotsky (1997) faz críticas às teorias que defendem a compensação biológica do defeito físico. Para ele, quem acredita que $o$ defeito da cegueira se compensa com a educação do ouvido e o tato está cometendo um equívoco, situando-se em um ponto de vista que se distancia do âmbito da pedagogia social. Na opinião do autor russo, a compensação biológica deve ser substituída pela idéia de compensação social do defeito. Por exemplo, a cegueira pode ser compensada em maior medida por outros estímulos, pois o mais importante é aprender a ler, e não ver as letras, é reconhecer as pessoas e compreendê-las, e não olhar em seus olhos.

A educação inclusiva é algo que vem se efetivando, no entanto tem provocado muitos questionamentos, principalmente quando se pensa na escola regular e se observa sua infra-estrutura física e, particularmente, seus recursos humanos. O interesse da autora do presente trabalho pelo tema surgiu a partir de alguns questionamentos como: a escola está se estruturando para receber e atender um aluno com necessidades educativas especiais? Os professores estão sendo preparados para lidar com as diferenças, com a singularidade e a diversidade de todos os alunos? Como é que está ocorrendo a implantação de projetos inclusivos? - etc. $O$ tema discutido neste trabalho esteve centrado na expectativa de responder a algumas dessas questões, 
bem como contribuir para o processo de inclusão escolar e para o bem-estar das pessoas com deficiência.

\section{Método}

\section{Participantes}

Essa pesquisa foi desenvolvida em duas escolas públicas de educação básica localizadas em uma cidade no interior do Estado do Paraná que possuem em suas salas de aula regulares alunos com necessidades educativas especiais. A opção por estas escolas deveu-se ao fato de a pesquisadora ter o conhecimento prévio de que elas estavam desenvolvendo projetos inclusivos. A amostra da pesquisa foi constituída por treze professores que atuavam nas escolas escolhidas. A maioria dos participantes era do sexo feminino e apenas um era do sexo masculino. Suas idades variavam entre 37 e 60 anos, sendo que a faixa de maior freqüência compreendeu professores entre 42 e 50 anos (seis). Todos os participantes tinham curso superior. Quanto à experiência profissional nas áreas de deficiência mental, visual, auditiva e física, constatou-se que os professores só a possuíam na área em que atuavam, ou seja, o professor que trabalhava com alunos deficientes mentais apenas nessa área é que tinha experiência, o mesmo ocorrendo com os demais professores.

A seleção dos participantes foi feita considerando-se o fato de terem em sua sala de aula alunos com necessidades educativas especiais, bem como o interesse e a disponibilidade em participar da pesquisa.

\section{Material}

Os materiais utilizados na presente pesquisa para coleta de dados foram os seguintes:

- Documento de anuência da escola: foi elaborado e entregue às escolas um documento solicitando a autorização da Direção;

- Termo de consentimento livre e esclarecido, documento que foi apresentado a cada um dos participantes, lido, preenchido e assinado por eles, ficando claro terem recebido informação sobre o propósito do estudo e consentido em participar dele;

- $\quad$ Ficha de identificação (professores), usada para obter informações sobre idade, sexo, formação acadêmica e experiência profissional dos participantes da pesquisa.

- Um questionário composto pelas seguintes questões:

1- Ocorreram mudanças na escola para implantação da inclusão escolar? No caso positivo, quais foram essas mudanças?

2- Há dificuldades quanto à implantação da educação inclusiva? Quais são elas?
3- Qual é o conhecimento que possui sobre as deficiências (mental, visual, auditiva e física) e sobre a inclusão escolar?

4- Você recebeu ou está recebendo algum preparo/capacitação para participar da inclusão escolar? Que tipo de preparo/capacitação recebeu ou está recebendo?

\section{Procedimento}

Como início do trabalho foi realizado o contato com a Direção da escola para solicitar sua autorização para a coleta de dados prevista pela pesquisa. Nesse pedido de autorização foi esclarecido que o nome da escola e a identidade dos participantes seriam preservados. Também foi explicado o trabalho que seria realizado (objetivos, método etc.) e ainda informado à Direção que o documento de autorização assinado seria apresentado ao Comitê Permanente de Ética em Pesquisa Envolvendo Seres Humanos da Universidade Estadual de Maringá (Processo - N.․ 074/2003).

Após o parecer favorável do Comitê de Ética, entrou-se em contato com os participantes da pesquisa na escola em que trabalhavam, para explicar seus objetivos, como também apresentar o termo de consentimento. Após sua anuência, foi-lhes entregue a ficha de identificação, a qual foi por eles preenchida. Em seguida foi-lhes entregue o questionário da pesquisa, que também foi respondido por eles na própria instituição em que trabalhavam, durante sua hora-atividade, na presença da pesquisadora.

\section{Resultados e Discussão}

A organização dos dados foi feita com base nos questionários aplicados. Estes dados foram examinados mediante análise de conteúdo que, segundo Bardin (1977, p.42), consiste em "um conjunto de técnicas de análise das comunicações, visando obter, por procedimentos sistemáticos e objetivos de descrição do conteúdo das mensagens, indicadores (quantitativos ou não) que permitam a inferência de conhecimentos relativos às condições de produção/recepção (variáveis inferidas) destas mensagens". Cabe frisar que, dentre as várias técnicas que contemplam a análise de conteúdo, a análise categorial foi a empregada para trabalhar com os dados desta pesquisa. Os dados foram categorizados, apresentados em tabela e discutidos com base no referencial teórico utilizado no presente estudo.

\section{Ocorreram mudanças na escola para implantação do projeto inclusivo}

Dimensões 
1- Sim: incluiu as respostas dos participantes que informaram terem ocorrido mudanças nas escolas com a implantação da inclusão escolar. Ex.: "sim", "sim alterações quanto ao espaço físico", etc.

2- Não: compreendeu as respostas dos participantes que apontaram não ter ocorrido nenhuma alteração na escola para implantação do projeto inclusivo Exs.: "não", "não recebi preparo nenhum", "espaço físico nenhum" etc.

Os dados apresentados na Tabela 1 mostram que $53,8 \%$ das respostas emitidas pelos participantes referemse à dimensão $\mathrm{sim}$, ou seja, são respostas nas quais informaram terem ocorrido algumas alterações na escola com a implantação da inclusão escolar. Os restantes $46,2 \%$ das respostas apontaram que a escola não passou por nenhuma mudança ao dar início a este processo. Esses resultados revelam haver escolas que passaram por alterações ao implantarem a educação inclusiva, mas também evidenciam muitas delas não realizaram nenhuma modificação, seja na infra-estrutura física seja na de recursos humanos.

Esse resultado se torna incoerente quando se traz para discussão a Declaração de Salamanca (1994), a qual trata dos princípios e leis para as necessidades educativas especiais e, dentre outras questões, acentua que as pessoas com necessidades educativas especiais devem ter acesso às escolas comuns e que estas deverão integrá-las numa pedagogia apta a atendê-las de acordo com suas especificidades (Abenhaim, 2005). Este documento deixa claro que as escolas que incluírem em salas de aula comuns alunos com algum tipo de deficiência necessitam muito mais do que apenas espaço físico apropriado. Cabe frisar que espaço físico adequado é imprescindível, mas não é suficiente quando se fala em incluir de fato pessoas com necessidades educativas especiais no sistema regular de ensino.

\section{Mudanças ocorridas na escola para implantação da inclusão escolar}

Dimensões

1- Alterações quanto ao espaço físico: incluíram as respostas dos participantes que informaram ter ocorrido mudanças na infra-estrutura no que diz respeito ao espaço físico - por exemplo: "ocorreram algumas mudanças no espaço físico", "construção de rampas com acesso a todos os pavilhões" etc.

2- Contratação de um professor de apoio para atender uma aluna com necessidades educativas especiais: reposta em que o participante informou que foi contratado um professor para atuar auxiliando o aluno de inclusão. Ex.: "contratação de professor de apoio permanente, $\mathrm{p} /$ aluna com múltiplas necessidades".

Os dados apresentados na Tabela 2 revelam que a dimensão prevalente quanto às mudanças ocorridas na escola para implantação da educação inclusiva refere-se à alterações quanto ao espaço físico, com 87,5\% das respostas. Estes dados mostram que as mudanças se relacionam quase exclusivamente ao aspecto físico. As respostas fornecidas pelos participantes deixam explícito que alterações tanto em estratégias quanto em metodologias de ensino, assim como preparação/capacitação de profissionais, não acorreram ao se dar início ao processo de inclusão de alunos com necessidades educativas especiais nestas escolas.

Tabela 1. Ocorrem mudanças na escola para implantação do projeto inclusivo

\begin{tabular}{lcc}
\hline \multirow{2}{*}{ Dimensões } & \multicolumn{2}{c}{ Respostas dos Participantes } \\
\cline { 2 - 3 } 1 - Sim & Freqüência & Porcentagem \\
2 - Não & 7 & 53,8 \\
Total & 6 & 46,2 \\
\hline
\end{tabular}

Tabela 2. Mudanças ocorridas na escola para implantação da inclusão escolar

\begin{tabular}{lcc}
\hline \multirow{2}{*}{ Dimensões } & \multicolumn{2}{c}{ Respostas dos Participantes } \\
\cline { 2 - 3 } & Freqüência & Porcentagem \\
\hline $\begin{array}{l}\text { 1-Alterações quanto ao espaço físico } \\
\text { 2-Contratação de um professor de apoio para atender } \\
\text { uma aluna com necessidades educativas especiais. }\end{array}$ & 7 & 87,5 \\
\hline Total & 1 & 12,5 \\
\hline
\end{tabular}


Torna-se importante destacar neste momento que inclusão não significa apenas juntar no mesmo espaço físico alunos com necessidades especiais e alunos nãoespeciais. As alterações físicas, embora imprescindíveis, não são suficientes para a real inclusão escolar. Neste sentindo, Gotti (1998) afirma que inclusão escolar implica muito mais do que apenas possibilitar um espaço físico comum a todos os alunos, sejam eles especiais ou não: requer também que todas as pessoas que compõem a comunidade acadêmica se envolvam na luta pela conscientização sobre o direito à cidadania. Essa autora coloca a sensibilização e a conscientização da comunidade acadêmica como pré-requisitos fundamentais para que se possa pensar de forma crítica este processo.

Nesta mesma perspectiva encontram-se Tesini e Manzini (1999), em cuja opinião um processo desta natureza envolve a definição de uma política que venha subsidiar princípios e práticas que possibilitem não apenas a entrada do aluno com necessidades educativas especiais na escola regular, mas também sua permanência com qualidade educativa, portanto, com normas uniformes sobre a igualdade de oportunidades para este tipo de aluno.

Infelizmente, observa-se que há muito mais ranços do que avanços. Os resultados aqui obtidos explicitam que a inclusão escolar tal como deveria ocorrer ainda não saiu do papel, pelo menos não nas escolas que fizeram parte deste estudo. Vale ressaltar também que inclusão escolar não envolve apenas a boa vontade dos profissionais diretamente envolvidos nesse processo, disposição que é importante, mas não suficiente. A inclusão requer, além de infra-estrutura física, no mínimo também infra-estrutura humana.

Destaca-se aqui também a posição de Veiga Neto (2005), segundo a qual qualquer tipo de inclusão, seja escolar ou não, envolve questões de ordem política, social e cultural. Acredita o autor que não basta incluir para serem eliminados os diferenciais de poder, de segregação, autoritarismo e exploração que permeiam a sociedade. Para ele, a maior dificuldade está em se conseguir uma escola que considere as diferenças culturais, isto é, não elimine as características culturais de cada grupo e compreenda que as diferenças acontecem num mundo de lutas, de posições e significados.

Torna-se cada vez mais clara a complexidade que envolve um projeto desta natureza, pois são muitos os aspectos nele envolvidos e não há como simplificá-lo e limitá-lo à conquista de espaço físico.

\section{Dificuldades quanto à implantação da educação inclusiva}

Dimensões

1- Não tem dificuldade: incluiu as respostas em que informaram não haver dificuldade no tocante à implantação e desenvolvimento desta proposta - por exemplo, "não".

2- Falta de preparo/capacitação profissional: incluiu as manifestações dos participantes de que não possuem conhecimento/informação para trabalhar com os alunos com necessidades educativas especiais, por exemplo: "a principal é a falta de preparo do professor", "falta conhecimento específico sobre a dificuldade do aluno", etc.

3- Falta de aceitação da inclusão: incluiu as respostas em que os participantes afirmaram haver pessoas que não aceitam a inclusão, por exemplo: "falta de aceitação de alguns pais", " falta de aceitação de alguns profissionais" etc.

4- Falta de infra-estrutura da escola: nesta dimensão foram inseridas as respostas em que os participantes apontaram 0 fracasso da escola e do sistema educacional. Ex.: "escola não possui estrutura para inclusão".

Tabela 3. Dificuldades quanto à implantação da educação inclusiva

\begin{tabular}{lcc}
\hline \multirow{2}{*}{ Dimensões } & \multicolumn{2}{c}{ Respostas dos Participantes } \\
\cline { 2 - 3 } & Freqüência & Porcentagem \\
\hline 1- Não tem dificuldade & 1 & 5,0 \\
2-Falta de preparo/capacitação profissional & 9 & 45,0 \\
3-Falta de aceitação da inclusão & 1 & 5,0 \\
4-Falta de infra-estrutura da escola & 5 & 25,0 \\
5-Falta estratégias/metodologias de ensino & 2 & 10,0 \\
adequadas às necessidades dos alunos inclusivos & & 10,0 \\
6-Falta de materiais didáticos/pedagógicos & 2 & 100,0 \\
específicos & 20 & \\
\hline Total & & \\
\hline
\end{tabular}


5- Faltam estratégias/metodologias de ensino adequadas às necessidades dos alunos inclusos: respostas em que informaram não dispor de estratégias e metodologias específicas para atender cada aluno - por exemplo: "falta de estratégias diferentes para ocorrer compreensão", "dificuldade no que se refere à metodologia; como trabalhar com este aluno integrado aos demais".

6- Falta de materiais didático-pedagógicos específicos: inclui as respostas nas quais se referiu que a escola não dispõe de materiais didáticos e pedagógicos para atender os alunos de inclusão - por exemplo: "falta de materiais didáticos específicos para atender as necessidades dos alunos especiais", "não recebemos material didático especial".

Os dados apresentados na Tabela 3 revelam que 45\% das respostas dos participantes sobre as dificuldades envolvidas na implantação da educação inclusiva referemse à dimensão falta de preparo/capacitação dos profissionais, respostas em que eles apontaram o despreparo e a dificuldade dos profissionais, especialmente do professor, para atender o aluno com necessidades educativas especiais em sala de aula comum. Seguiram-se $25 \%$ para a dimensão falta de infraestrutura da escola; $10 \%$ para a dimensão falta de estratégias e metodologias adequadas às necessidades dos alunos inclusos.

Conforme revelam esses resultados, para boa parte dos participantes o que está dificultando o processo de inclusão dos alunos com necessidades educativas especiais no ensino regular são a falta de preparo dos profissionais e a insuficiência da infra-estrutura das escolas para receber e atender esses alunos.

Estes dados deixam evidente que os professores participantes da pesquisa não estão aptos para trabalhar com a diversidade em sua sala de aula, o que certamente os leva a se sentirem inseguros, preocupados e desamparados em sua profissão. Neste sentido, Glat, Magalhães e Carneiro (1998) contribuem ao afirmarem que a escola inclusiva só poderá se concretizar quando os professores estiverem aptos a trabalhar com a diversidade dentro sala de aula. A escola deve, então, estar provida de recursos humanos, pedagógicos e materiais adequados às necessidades e especificidades de cada aluno.

Esses resultados sugerem que nem mesmo os quesitos básicos - como formação/capacitação de professores, materiais didático-pedagógicos, adaptações curriculares - foram providenciados por estas escolas ao se implantar a educação inclusiva. Destaca-se que estas não são as únicas questões importantes a serem discutidas e debatidas quando o assunto é a inclusão escolar, mas elas são imprescindíveis.

\section{Conhecimento dos participantes sobre as deficiências e sobre a inclusão}

Dimensões

1- Nenhum conhecimento: envolveu as respostas em que os participantes afirmaram não possuir nenhum conhecimento sobre deficiências e inclusão - por exemplo: "nenhum"; "não tenho conhecimento", etc.

2- Pouco conhecimento: aglutinou as respostas dos participantes que informaram conhecer muito pouco sobre as deficiências e a inclusão - por exemplo: "sobre as deficiências meu conhecimento é a nível básico, que foi estudado durante o curso de ciências"; "o conhecimento é de palestras, conversas com profissionais da área", etc.

3- O conhecimento de um leigo: aglutinou as respostas de que o conhecimento sobre o assunto é o mesmo de um leigo.

Os dados da Tabela 4 mostram que $66,7 \%$ das respostas emitidas pelos participantes sobre 0 seu conhecimento em relação às deficiências e à inclusão referem-se à dimensão pouco conhecimento, seguindo-se as respostas para a dimensão nenhum conhecimento com $25 \%$. Conforme revelam esses resultados, a maioria dos participantes informou ter pouco conhecimento sobre as deficiências e a inclusão, ou seja, apenas os adquiridos em palestras, conferências, na graduação, na mídia, etc.

Tabela 4. Conhecimento dos participantes sobre as deficiências e sobre a inclusão

\begin{tabular}{lcc}
\hline \multirow{2}{*}{ Dimensões } & \multicolumn{2}{c}{ Respostas dos Participantes } \\
\cline { 2 - 3 } & Freqüência & Porcentagem \\
\hline 1 - Nenhum conhecimento & 3 & 20,0 \\
2 - Pouco conhecimento & 10 & 66,7 \\
3 - O conhecimento de um leigo & 2 & 13,3 \\
\hline Total & 8 & 100,0 \\
\hline
\end{tabular}


Tabela 5. Preparação/capacitação para participar da inclusão escolar

\begin{tabular}{lcc}
\hline \multirow{2}{*}{ Dimensões } & \multicolumn{2}{c}{ G1 } \\
\cline { 2 - 3 } & Freqüência & Porcentagem \\
\hline 1 - Sim & 10 & 76,9 \\
2 - Pouco & 3 & 23,1 \\
\hline Total & 13 & 100,0 \\
\hline
\end{tabular}

Respostas também muito significativas são as que pertencem às dimensões nenhum conhecimento $\mathrm{e}$ conhecimento de um leigo. Aqui os participantes deixaram claro que nada ou quase nada conhecem sobre estes assuntos, pois o pouco conhecimento que possuem provém do seu cotidiano, e não do meio acadêmico e científico.

Esses resultados levam aos seguintes questionamentos: como é possível profissionais que têm em sua sala de aula alunos deficientes incluídos não terem nenhum conhecimento sobre as deficiências e sobre a inclusão? Como estão trabalhando com estes alunos? Parece que está havendo um faz-de-conta: faz-se de conta que se trabalha e ensina e faz-se de conta que se aprende. Isto possibilita inferir que o que está sendo veiculado pela mídia quanto à pessoa com necessidades educativas especiais e à sua inclusão, especificamente na escola, nem sempre reflete o que vem acontecendo na prática. Os participantes deste estudo evidenciaram que pouco ou nada conhecem sobre estes alunos, e então se pergunta: como podem eles desenvolver um trabalho que realmente thes possibilite aprendizagem e desenvolvimento?

Com certeza, essa inclusão escolar que vem se concretizando nas escolas compreendidas neste estudo não é a que se deseja; ao contrário, o que precisa ser defendido e conquistado é uma inclusão em que os profissionais saibam ensinar todas as crianças, sejam elas especiais ou não. Necessita-se, em caráter de urgência, acabar com o "faz-de-conta-que-se-ensina" e o "faz-deconta-que-se-aprende" na escola, principalmente no que diz respeito à educação escolar do aluno com necessidades educativas especiais, pois este aluno, assim como qualquer outro, tem condições de aprender e se desenvolver. Vale destacar neste momento a compreensão de Vygotsky (1997) sobre a criança deficiente. Para o pesquisador russo essa criança é um ser capaz e com condições de aprendizagem e desenvolvimento semelhantes às da criança "normal". Em seu entendimento, o social se sobrepõe ao biológico, tanto que defendia que a educação social acabaria vencendo o defeito, o biológico. A ênfase, portanto, não se encontra no defeito, mas sim nas possibilidades de aprendizagem que o meio propiciará a esta criança.
Vale ressaltar ainda que, para Vygotsky (1997), o melhor local para uma criança com deficiência estudar era a escola regular. $\mathrm{O}$ autor criticava as escolas especiais de sua época, pois estas, ao terem como princípio adaptar-se às deficiências da criança, acabavam por segregá-la. Para ele, a principal função da escola era exatamente o contrário, isto é, vencer a deficiência principalmente no campo social. A tarefa da educação, portanto, se constituía em introduzir a criança deficiente na vida social e por esse meio criar a compensação de sua insuficiência física.

\section{Preparação/capacitação para participar da inclusão escolar}

Dimensões

1- Não: incluiu as respostas em que os participantes afirmaram não ter recebido nenhum preparo para participar da inclusão escolar - por exemplo: "nenhum preparo"; "não", etc.

2- Pouco: nessa dimensão os participantes relataram que praticamente não receberam preparo para exercer tal função: - por exemplo: "pouco", "veio uma pessoa do núcleo algumas vezes", "tivemos uma palestra sobre $o$ assunto" etc.

Os dados apresentados na Tabela 5 revelam que a maioria das respostas dos participantes sobre o seu preparo/capacitação para participar da inclusão escolar pertence à dimensão não $(76,9 \%)$, ficando os restantes $23,1 \%$ para a dimensão pouco.

Esses resultados mostram que a maioria dos participantes não foi capacitada para trabalhar com alunos que possuem necessidades educativas especiais. Segundo eles, os poucos conhecimentos que possuem foram adquiridos em palestras e cursos rápidos, em que foram feitos alguns comentários sobre o assunto. Tais resultados revelam que estas escolas encontram-se praticamente desprovidas da infra-estrutura física e humana necessária à participação em projetos inclusivos, e conduzem aos seguintes questionamentos: os professores não precisam de preparo/capacitação para participar da inclusão? O conhecimento que possuem para trabalhar com os alunos "normais" é suficiente? Para incluir, basta proporcionar o mesmo espaço?

Esses dados levam a pensar que é muito difícil ser colocado em prática o que está registrado no papel como lei que rege o Sistema Educacional Brasileiro, pois a Lei de 
Diretrizes e Bases da Educação - LDB 9394/96 - afirma em seu artigo $3^{\circ}$ que os alunos terão garantido um padrão de qualidade de ensino, sejam eles com necessidades educativas especiais ou não. Também vale lembrar que nos documentos que tratam das leis e das políticas da educação especial - como, por exemplo, a Declaração de Salamanca (1994) - encontra-se que as escolas devem conhecer e responder diversas necessidades dos alunos assegurando a estes uma educação de qualidade, que Ihes proporcione aprendizagem por meio de currículo apropriado, modificações organizacionais, estratégias de ensino, uso de recursos adequados, etc.

Os resultados aqui obtidos sugerem que na prática isto não vem acontecendo. A conquista dos alunos deficientes inseridos nestas escolas, até o momento, parece ter consistido apenas em ocupar o mesmo espaço físico que ocupam os alunos considerados "normais", isto é, em poder se matricular e freqüentar a classe comum do sistema regular de ensino. Um ensino de qualidade e que atenda a todas as suas necessidades e especificidades certamente ainda não foi alcançado.

\section{Considerações finais}

Os principais resultados revelaram que, segundo a maioria dos participantes, ocorreram mudanças na escola com a implantação da educação inclusiva, porém houve um percentual significativo de respostas informando que a escola não sofreu nenhuma alteração ao incluir alunos com necessidades educativas especiais em seu contexto. Também mostraram que as alterações ocorridas nas escolas relacionam-se quase exclusivamente à infraestrutura física, e que a falta de preparo/capacitação dos profissionais da educação, de infra-estrutura da escola e de estratégias e metodologias de ensino adequadas a esse aluno está dificultando o processo de inclusão.

Os dados apontaram ainda que a maioria dos participantes possui pouco conhecimento sobre as deficiências e sobre a inclusão escolar e que alguns deles nada conhecem sobre estes assuntos. Isto revela que praticamente nenhum dos participantes da pesquisa recebeu qualquer tipo de preparo ou qualificação que pudesse auxiliá-los no atendimento aos alunos com necessidades educativas especiais em sua sala de aula.

Conclui-se que as escolas que participaram deste estudo ainda não possuem infra-estrutura adequada, principalmente no que diz respeito aos recursos humanos, para desenvolverem projetos inclusivos. Disso se pode inferir que as pessoas com necessidades educativas especiais matriculadas nestas escolas, até 0 momento, conquistaram apenas 0 direito de entrar pelos portões da escola regular, mas o principal, que seria eliminar o caráter excludente dessa escola, ainda não se conseguiu uma educação que possibilite aprendizagem e desenvolvimento. É evidente que os alunos com necessidades educativas especiais destas escolas não estão sendo atendidos com uma educação que thes possibilite aprendizagem e desenvolvimento, condizente com o projeto efetivo de inclusão, pois, como estão, pode haver para eles mais prejuízos do que benefícios.

O que se defende aqui é um ensino de qualidade e que a escola não seja excludente, mas deve-se ter claro que incluir no contexto escolar uma pessoa há muito tempo excluída do contexto social requer muito mais do que apenas proporcionar-Ihe o mesmo espaço físico. Uma escola realmente inclusiva não é aquela que apenas não exclui, dentro da sala de aula, o aluno especial ou diferente, mas a que consegue respeitar e aceitar sua diversidade e também the garantir aprendizagem e desenvolvimento. Considerando-se que a principal função da escola é ensinar, ou melhor, propiciar a todos os seus alunos a oportunidade de aprender, não se pode deixar de exigir que ela cumpra este seu papel, seja com a criança normal seja com a que tem necessidades educativas especiais.

\section{Referências}

Abenhaim, E. (2005). Os Caminhos da inclusão: breve histórico. Em A. M. Machado, A. J. Veiga Neto, M. V. O. Silva, R. G. Prieto, W. Rannã \& E. Abenhaim (Orgs.), Psicologia e Direitos Humanos: Educação Inclusiva, direitos humanos na escola (pp. 39-53). São Paulo: Casa do Psicólogo.

Bardin, L. (1977). Análise de conteúdo. (L. A. Reto \& A. Pinheiro, trad.). Lisboa: Edições 70.

Brasil. (2000). LDB: Lei de Diretrizes e Bases da Educação: Lei 9.394/96. Apresentação Esther Grossi. Rio de Janeiro: DP\&A.

Gasparetto, M. E. R. F. (2001). Visão subnormal em escolas públicas: conhecimentos, opinião e conduta de professores e diretores do ensino fundamental. Tese de Doutorado, Universidade Estadual de Campinas, Campinas, São Paulo.

Glat, R., Magalhães, E. F. C. B., \& Carneiro, R. (1998). Capacitação de professores: primeiro passo para uma educação inclusiva. Em M. C. Marquezine, M. A. Almeida, E. D. O. Tanaka, N. N. R. Mori \& E. M. Shimazaki (Orgs.), Perspectivas multidisciplinares em educação especial (pp. 373-378). Londrina: Ed. UEL.

Gotti, M. O. (1998). Integração e Inclusão: nova perspectiva sobre a prática da educação especial. Em M. C. Marquezine, M. A. Almeida, E. D. O. Tanaka, N. N. R. Mori \& E. M. Shimazaki (Orgs.), Perspectivas multidisciplinares em educação especial (pp. 365-372). Londrina: Ed. UEL.

Machado V. (2003). Repercussões da proposta "Educação Inclusiva" a partir do discurso de professoras de educação especial da rede pública estadual paulista. Dissertação de Mestrado, Universidade de São Paulo, São Paulo, São Paulo. 
Mazzoni, A. A., Torres, E. F., \& Andrade, J. M. B. (2000). Sobre acesso e a permanência de estudantes universitários com necessidades educativas especiais $\mathrm{Em} \mathrm{N}$. N. R. Mori, M. C. Marquezini, M. L. P. Guhur, \& E. M. Shimazaki (Orgs.), Educação Especial: olhares e práticas (pp. 225-233). Londrina: Ed. UEL.

Mendes, E. G. (2002). Perspectivas para construção da escola inclusiva no Brasil. Em M. S. Palhares \& S. C. F. Marins (Orgs.), Escola Inclusiva (pp. 61-85). São Carlos: EduFSCar.

Mrech, L. M. (2001). Educação inclusiva: realidade ou utopia. Disponível:

www.educacaoonline.pro.br/educação_inclusiva_realidade_ou_uto pia.html?f_id.

Paula, L. A. L. (1996). Ética, cidadania e educação especial. Revista Brasileira de Educação Especial, 12(4), 91-107.

Rey, B. (2003). A inclusão de alunos com necessidades aplicadas nas series iniciais do ensino fundamental - um olhar na sala de aula. Dissertação de Mestrado, Universidade de Sorocaba, Sorocaba, São Paulo.
Tesini, S. F., \& Manzini, E. J. (1999). Perspectivas de professores que trabalham com deficientes mentais sobre a proposta de inclusão na rede oficial de ensino. Em E. J. Manzini (Org.), Integração do aluno com deficiência: perspectiva e prática pedagógica, (pp. 85-96). Marília: UNESP.

Veiga Neto, A. (2005). Quando a inclusão pode ser uma forma de exclusão. Em A. M. Machado, A. J. Veiga Neto, M. V. O. Silva, R. G. Prieto, W. Rannã \& E. Abenhaim (Orgs.), Psicologia e Direitos Humanos: Educação Inclusiva, direitos humanos na escola (pp. 55-70). São Paulo: Casa do Psicólogo.

Vygotsky, L. S. (1997). Fundamentos de Defectologia. Obras escogidas, Tomo V. (J. G. Blanck, trad.). Madrid: Visor Dist. S. A.

Recebido em: 06/12/2007

Revisado em: 08/12/2008

Aprovado em: 15/12/2008

\section{Sobre a autora}

Nilza Sanches Tessaro Leonardo (nstessaro@uem.br) - Doutora em Psicologia; professora do curso de Psicologia da Universidade Estadual de Maringá -UEM

Avenida Governador Parigot de Souza 184, apto 101, CEP 87013300 Maringá -PR 